\title{
Percepção de CONFlito eM uma família Recasada CONSTituída POR UM FILHO COM PARALISIA CEREBRAL
}

\author{
PERCEPTION OF CONFLICT IN A STEPFAMILY WITH A CHILD WITH CEREBRAL \\ PALSY
}

\author{
Hilda Rosa Moraes de FREITAS ${ }^{1}$ \\ Simone Souza da Costa SILVA ${ }^{2}$ \\ Fernando Augusto Ramos PONTES 3
}

\begin{abstract}
RESUMO: o aumento no número de separação/divórcio favorece o surgimento de novas estruturas familiares. Nesse sentido, o recasamento desponta como uma possibilidade de ordenamento do grupo familiar, que impõe à nova família uma reorganização, sobretudo nas vidas afetiva, social e econômica, assim como maior flexibilidade para negociar questões de associação, espaço, autoridade e tempo. O objetivo deste artigo foi descrever a estrutura e a dinâmica de uma família recasada, na qual há uma criança com paralisia cerebral, a partir de suas representações acerca de situações de conflito. Neste estudo de caso, foi pesquisada uma família, constituída, por três membros, mãe, filho e padrasto; foram aplicados um roteiro de entrevista semiestruturado e o Family System Test (FAST). Os escores obtidos no FAST demonstraram proximidade na díade mãe-filho e distanciamento na díade padrasto-enteado, com a hierarquia concentrada na mãe; quanto à flexibilidade das fronteiras, a percepção do casal indicou fronteiras rígidas tanto no sistema familiar quanto no parental, diferenciando-se da percepção do filho sobre o sistema familiar com uma fronteira difusa. Portanto, alguns fatores destacados na literatura e presentes nessa família como: diferença no ciclo de vida do casal; pouco tempo de união; bagagem emocional entre mãe e filho, associados às demandas de cuidado da criança, seus recursos biopsicológicos e disposições; configuraram um padrão rígido, com baixa flexibilidade, o que dificulta a inserção do padrasto no grupo e, consequente, assunção de co-paternidade nos cuidados e criação do enteado.
\end{abstract}

PALAVRAS-CHAVE: Educação Especial. Paralisia Cerebral. Conflito familiar. Dimensão da família.

\begin{abstract}
The increase in the number of separation/divorce has favored the emergence of new family structures. Thus, remarriage becomes a possibility for developing the family group which requires emotional, social and economic reorganization of the family, as well as greater flexibility to negotiate association, space, time and authority. The objective of this article was to describe the structure and dynamics of a stepfamily having a child with cerebral palsy, based on the members' representations of conflict situations. In this case study focused on a family, made up of three members: mother, son and stepfather. A semi-structured interview and the Family System Test (FAST) were applied. The FAST scores showed closeness in the mother-child dyad and distance in the stepfather-stepson dyad, with the hierarchy focused on the mother figure. As to the flexibility of boundaries, the couple's perception indicated rigid boundaries, both for the family and for parental systems, while the child's perception of the family system revealed diffused boundaries. Therefore, some factors highlighted in the literature and evident in this family such as differences in the couple's life cycle, short period of marriage, emotional baggage between mother and son, added to demands of child care, resources and biopsychological provisions, constituted a rigid standard with low flexibility, which made it difficult to include the stepfather in the group, resulting in less commitment to co-parenting in the care and education of the stepchild.
\end{abstract}

KEYWORDS: Special Education. Stepfamily. Cerebral Palsy. Familiar Conflict.

\footnotetext{
${ }^{1}$ Profa. Assistente I do Instituto Ciberespacial da Universidade Federal Rural da Amazônia. hilda.freitas@yahoo. com.br

2 Profa. Adjunta III do Programa de Pós-Graduação em Teoria e Pesquisa do Comportamento da Universidade Federal do Pará. symon@ufpa.br

${ }^{3}$ Prof. Associado III do Programa de Pós-Graduação em Teoria e Pesquisa do Comportamento, Universidade Federal do Pará. fernando.pontes@pesquisador.cnpq.br
} 


\section{INTRODUÇÃo}

Embora tradicionalmente a psicologia do desenvolvimento tenha focado seu olhar no desenvolvimento padrão, nos últimos anos é evidente o crescimento do interesse pelo conhecimento acerca dos períodos de estabilidade e mudança vividos por pessoas com necessidades especiais. Esta perspectiva sustenta-se na noção de que apesar dos limites impostos, todas as pessoas carregam em si o potencial para se desenvolver.

Com base nesta potencialidade para o desenvolvimento e na compreensão de que este se processa necessariamente em um dado contexto (BRONFENBRENNER, 1999; BRONFENBRENNER; CECI, 1994; BRONFENBRENNER; EVANS, 2000) entende-se que o conhecimento, acerca das especificidades contextuais daqueles que possuem necessidades especiais, pode contribuir com a construção de tecnologias favorecedoras de qualidade de vida para esta população.

Além da necessidade de se conhecer os contextos (físico, social e histórico) onde as pessoas em desenvolvimento estão inseridas, Bronfenbrenner (BRONFENBRENNER, 1999; BRONFENBRENNER; EVANS, 2000; BRONFENBRENNER; MORRIS, 1998), em seu modelo que denominou bioecológico, destaca a importância das características da pessoa como um componente que influencia em sua trajetória. Estas características são produzidas a partir de mecanismos biológicos assim como adquiridas por meio da experiência e tem influência fundamental no direcionamento e no conteúdo dos processos proximais. Dessa forma, ao mesmo tempo em que a pessoa é influenciada pelo ambiente, o influencia, o transforma, por meio de seus recursos biopsicológicos, disposições e demandas.

Nesse sentido, tal como qualquer criança, as características daquelas com paralisia cerebral (PC), produzem demandas aos contextos onde estão inseridas de acordo com suas disposições e recursos, estabelecendo assim processos proximais peculiares ao seu desenvolvimento, pois é 'na interação, que a pessoa constrói sentidos, os quais definem a sua forma particular de ação nos diversos contextos' (apud PRATTI et. al., 2008, p.162). Daí o destaque atribuído por Bronfenbrenner aos processos proximais que são compreendidos como os motores do desenvolvimento (BRONFENBRENNER; MORRIS, 1998).

A importância atribuída pelo modelo às relações estabelecidas entre ambiente e pessoa requer o conhecimento das características destes componentes. Por isso, além da compreensão acerca do ambiente, saber sobre o desenvolvimento de pessoas com necessidades especiais implica no conhecimento de suas características, recursos biopsicológicos e disposições. Dessa forma, a descrição dos contextos, da pessoa desenvolvente e de seus parceiros de interação permitirá entender os processos proximais que estabelecerão sua trajetória desenvolvimental. 
Identificar características gerais das crianças com PC constitui uma tarefa árdua, pela dificuldade em encontrar crianças, com o mesmo padrão comportamental. De acordo com Geralis (2007) dentre os comprometimentos decorrentes da PC pode-se observar aqueles referentes às capacidades de locomoção, equilíbrio, coordenação e/ou precisão dos movimentos, sem prejuízo dos músculos em si ou da medula espinal. No entanto, dependendo da área afetada e do grau, pode acarretar outras complicações como: atraso cognitivo, distúrbios da fala, surdez, distúrbios na visão e convulsões.

O efeito das características da criança, no contexto, está associado ao modo como este se organizará diante da pessoa com PC. Isto é válido em se tratando de qualquer ambiente que esta criança participe; no entanto quando se trata do grupo familiar, onde a criança participa de modo estável e consistente, estes efeitos se estendem ao longo do tempo. Conforme Basil (2004), a família pode se adaptar positivamente aos estressores derivados das necessidades específicas da criança com PC mesmo que isso demande tempo.

As características dos indivíduos que compõe o grupo familiar constituem em parte a estrutura e a dinâmica de seu funcionamento. Deste modo, as peculiaridades relacionais encontradas nos diferentes sistemas familiares representam o modo como o grupo se organiza a partir das características de cada um. Alguns estudos (VITANZA; GUARNACCIA, 1999; FREITAS et. al., 2005) que investigam famílias de crianças com necessidades especiais tem contribuído na medida em que expõe suas estratégias relacionais diante das demandas geradas pelas limitações de um de seus membros.

As mudanças, decorrentes da chegada de um filho com necessidades especiais (crise não normativa), por exemplo, configuram-se momentos de transição no ciclo de vida familiar, alterando o equilíbrio desse sistema, o que pode gerar conflitos dentro dos subsistemas e/ ou entre estes (MINUCHIN, 1988).

A forma encontrada pela família para resolver os conflitos dependerá das estratégias relacionais de cada membro, da forma como a família resolveu os conflitos anteriores e de como a estrutura familiar se reorganizou após esse período de descontinuidade. O resultado dos conflitos, enfrentados pela família, subsidiará padrões relacionais, que podem ser disfuncionais ou funcionais ao contexto familiar que repercutirá na proximidade da interação e nas trocas afetivas do grupo, podendo gerar novos conflitos ou novas estratégias de enfrentamento.

As estratégias encontradas pelas famílias para enfrentar as demandas tem sido associadas, sobretudo com a dinâmica e a estrutura do funcionamento familiar (GEHRING, 1993; GEHRING; MARTI, SIDLER, 1994). Segundo Minuchin (1990), a estrutura refere-se às sequências comportamentais que com o tempo tornam-se padrões que caracterizam o contexto familiar, estabelecendo regras, muitas vezes implícitas, dos papéis de cada membro, sendo composta por vários subsistemas (unidades baseadas em: função, papel, geração, sexo e interesse). 
A participação dos membros, nos subsistemas, se dá com base nos critérios de coesão e hierarquia, (GEHRING, 1993, NICHOLS; SCHWARTZ, 2007), que modulam o contato (fronteira) entre os subsistemas e entre o sistema familiar e o ambiente externo, permitindo o desenvolvimento de habilidades interpessoais, em seus membros. A coesão é definida como uma fronteira emocional entre os membros (GEHRING, 1993), já a hierarquia refere-se ao poder de decisão, ao grau de influência exercido por um membro da família sobre os demais (GEHRING, 1993).

A dinâmica de funcionamento familiar, ou seja, o movimento que ocorre no interior da estrutura (BUCHER, 2005 apud SILVA, 2006), dependerá do grau de emaranhamento ou distanciamento das fronteiras do grupo. Neste sentido, a dinâmica está atrelada à estrutura familiar, ou seja, em uma família nuclear, a dinâmica é diferente daquela de uma família extensa, assim como de uma recasada (CARTER; MCGOLDRICK, 2007).

Esta perspectiva de Carter e McGoldrick (2007) se remete a noção de família como um sistema aberto que estabelece trocas com os contextos em que estão inseridas. Portanto, as mudanças vividas pela sociedade, nas últimas décadas, influenciaram os padrões relacionais intra-familiares. Pois, na medida em que se alteram os modelos de família, pelo aumento do número de separações seguidas do crescente número de recasamentos, altera-se a estrutura e a dinâmica dos sistemas familiares.

\subsection{O RECASAMENTO E O PROCESSO DE NEGOCIAÇÃO DE CONFLITOS NO CONTEXTO FAMILIAR}

Em se tratando de família recasada formada pela união de dois adultos, para a qual um ou ambos trazem pelo menos um filho de uma relação anterior (GUERRIERO; OLIVEIRA; SOUZA, 1999), a complexidade não se dá apenas no arranjo familiar, que pode ser constituído por oito avós, irmãos, meio-irmãos, filhos da mulher do pai, filhos do marido da mãe, etc., mas também pelo estabelecimento de novos vínculos e a necessidade de definição de papéis entre conjugues, enteados e filhos e entre estes e os pais biológicos.

As dificuldades na organização desse novo arranjo podem levar os conjugues a permanecerem no padrão de família nuclear, o que é prejudicial na medida em que, se mantém uma união entre os membros da família, que exclui pais ou filhos biológicos, levando a competições entre padrasto/madrasta e enteados pela atenção do cônjuge (CARTER; MCGOLDRICK, 2007). Daí a necessidade de se estabelecer um novo modelo familiar cuja base é o vínculo conjugal, o qual ordenará as famílias numa nova estrutura.

A estrutura consequente do recasamento deve propiciar fronteiras permeáveis entre os subsistemas que permitam a negociação de papéis entre os conjugues sem negligenciar a influência dos pais biológicos. Algumas das dificuldades levantadas por Carter e McGoldrick (2007) na estruturação das fronteiras são as questões de: associação (identificação como membro da família, 
sentimento de pertencer $a$, o que no caso dessa estrutura familiar pode demorar de três a cinco anos); espaço (qual é o meu espaço? A qual lugar eu realmente pertenço?); autoridade (quem está realmente no comando? Da disciplina? Do dinheiro? Das decisões? etc.) e tempo (a quem dedicar meu tempo? - e quanto - e quanto tempo eu recebo deles?).

A complexidade dessa estrutura não se dá somente pela reorganização dos papéis entre os conjugues, mas também pela bagagem emocional, trazida pelo casal para a relação. Pois com o recasamento além da bagagem emocional da família de origem, a pessoa leva consigo as bagagens do casamento anterior, do processo de separação e do período entre os casamentos, o que requer flexibilidade e tolerância entre os membros (CARTER; MCGOLDRICK, 2007).

Conforme destacado na literatura, 'a família recasada é uma família que se constituiu de perdas, de modo que é muito importante que as mesmas sejam reconhecidas e também elaboradas' (apud CANO et al., 2009, p.218). Sendo assim, é importante considerar, entre outros fatores, o tempo transcorrido entre o divórcio e o recasamento; como os membros da família vivenciaram o processo do divórcio; presença/ausência de rede de apoio (ARAÚJO; DIAS, 2002); o tipo de vínculo constituído entre pais e filhos, antes da separação e diferenças no ciclo de vida entre os conjugues no recasamento (SOUZA, 2000; RAMIRES, 2004).

Nesse sentido orecasamento, assim como outros acontecimentos marcantes no ciclo de vida da família, como a separação/divórcio e a monoparentalidade, provoca reorganizações na vida afetiva, social e econômica de todos os membros do grupo familiar (RAMIRES, 2004), que podem ser positivas ou negativas. A expressão de conflitos neste contexto não é um fator negativo no grupo, mas sim a forma como esse conflito é manejado pelos envolvidos.

Além de questões peculiares à transição de uma estrutura monoparental ou nuclear para a configuração de uma família recasada, deve-se considerar as características dos novos membros com os quais serão construídos vínculos. No caso de um filho com necessidades especiais, os fatores citados anteriormente tanto no processo de transição como na constituição do novo grupo familiar serão influenciados por suas disposições, demandas e recursos biopsicológicos, que organizarão não somente suas relações parentais, mas também influenciarão a nova estrutura familiar.

Dessa forma o objetivo desta pesquisa foi descrever a estrutura e a dinâmica de uma família recasada, que tem uma criança com paralisia cerebral, a partir das representações dos membros do grupo familiar acerca de situações de conflito vividas no grupo. 


\section{MÉTodo}

\subsection{Participantes}

Optou-se nesta pesquisa pela realização de um estudo de caso único (YIN, 2005). Neste sentido o participante desta investigação é o grupo familiar que apresentou a seguinte configuração:

\begin{tabular}{|l|l|l|l|l|}
\hline Papel Familiar & Idade & Ocupação atual & Escolaridade & Renda (R\$) \\
\cline { 1 - 4 } Mãe & 34 & Serviços gerais & Ensino Médio Completo & \multirow{2}{*}{500,00} \\
\cline { 1 - 3 } Padrasto & 25 & Desempregado & Ensino Médio Completo & \\
\cline { 1 - 4 } Filho & 13 & Estudante & Cursando a 3 ${ }^{\circ}$ série do E.F. & \\
\cline { 1 - 3 }
\end{tabular}

Quadro 1 - Família estudada

Embora viva com a mãe e o padrasto, vale dizer que Davi ${ }^{4}$ mantinha ao longo do dia trocas interacionais com os membros de sua família estendida como, avó materna, tios, tias e primos. Isto ocorreu porque sua mãe trabalhava em dois turnos e sua avó, que morava ao lado, prestava-lhe cuidados como alimentação, higiene pessoal, etc.

\subsection{Ambiente}

O ambiente utilizado para a execução da pesquisa foi a casa de Davi, composta de três cômodos, da seguinte forma: sala, onde fica a cama do casal e uma estante com televisão; cozinha, onde fica sua cama separada dos demais móveis (fogão, geladeira e mesa) por uma cortina e um espaço para a construção de um banheiro, já que durante o período da coleta de dados as atividades de higiene pessoal eram feitas na casa da avó materna de Davi.

\subsection{INSTRUMENTOS}

Os instrumentos de coleta de dados foram: Roteiro de Entrevista Semiestruturado e Family System Test - FAST.

\subsubsection{Roteiro de Entrevista Semiestruturado}

O roteiro de entrevista foi inspirado no Inventário Sociodemográfico (ISD) (MENDES et al., 2008) e construído com 10 itens acerca de: identificação dos participantes, posição no grupo, renda, escolarização, ocupação, presença/ ausência de rede de apoio, atividades sociais e lazer. Adicionalmente foram incluídas questões referentes ao momento do diagnóstico de PC; tipos de recursos utilizados no tratamento, entre outros.

\footnotetext{
${ }^{4}$ Nome fictício para resguardar a identidade do participante, conforme termo de consentimento livre e esclarecido assinado pelo responsável.
} 


\subsubsection{FAmily System TeSt - FAST}

Trata-se de um teste que tem por finalidade descrever e analisar a estrutura e a dinâmica das relações familiares, por meio da configuração das fronteiras entre os sistemas (familiar, fraternal e parental), a partir das variáveis coesão e hierarquia (GEHRING, 1993). Apesar deste instrumento não ter sido validado no Brasil, tem sido utilizado por vários pesquisadores (FLECK; WAGNER, 2003; FALCÃO, 2006; PELISOLI; TEODORO; DELL'AGLIO, 2007).

O material de aplicação do teste consiste em um tabuleiro monocromático $(45 \mathrm{~cm} \times 45 \mathrm{~cm})$ dividido em 81 quadrados $(5 \mathrm{~cm} \times 5 \mathrm{~cm}) ; 12$ figuras, sendo seis masculinas e seis femininas, caracterizadas assim pela sua forma talhada em madeira, tendo no rosto a identificação dos olhos e da boca; e 18 blocos cilíndricos do mesmo

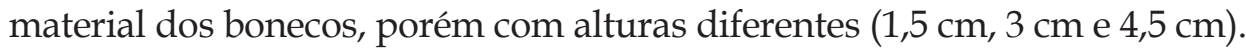

Acompanhando esse material há um protocolo, com dados de identificação do participante e três momentos, nos quais ele representará sua família. Inicialmente, ele a representará de forma típica, em seguida de forma ideal e por último, numa situação de conflito. Destaca-se que para este estudo será abordado apenas a representação de conflito.

As variáveis coesão e hierarquia são analisadas nas três representações para todos os sistemas (parental, fraternal e familiar), sendo que a coesão é calculada pela proximidade entre os bonecos dispostos no tabuleiro, de forma adjacente, e a hierarquia pelo número e tipo de cilindros utilizados na base dos bonecos, representando diferentes alturas. Após os cálculos de coesão e hierarquia pode-se avaliar as estruturas relacionais de cada grupo, dispondo-as em um continuum (equilibrada, equilíbrio instável e desequilibrada) Há também dois conceitos decorrentes dessas análises que são a inversão de hierarquia ${ }^{5}$ e a coalizão transgeracional ${ }^{6}$, os quais permitem identificar a flexibilidade dos sistemas, a partir de suas fronteiras.

\subsection{Cuidados ÉTICos}

Antes da inserção do pesquisador no contexto estudado, o projeto foi submetido, ao Comitê de Ética da Universidade Federal do Pará; recebendo o aceite sob o protocolo 138/07. A partir daí, iniciou-se a habituação no contexto escolar, para o estabelecimento de contato com as famílias e sua solicitação para a participação neste estudo. Diante da concordância, procedeu-se a assinatura do Termo de Consentimento Livre e Esclarecido pelo responsável que aceitou a inclusão de seu filho e família na pesquisa.

\footnotetext{
${ }^{5}$ A inversão de hierarquia (hierarchy reversal) ocorre quando a figura da criança fica com maior hierarquia que a figura de um dos pais (GHERING, 1993).

${ }^{6}$ A coalizão transgeracional (cross-generational coalition) ocorre se a relação no subsistema parental (pai-mãe) é menos coesa que qualquer uma da díade pai-criança ou mãe-criança (GHERING, 1993).
} 


\subsection{Procedimentos}

O primeiro momento foi de seleção e contato com uma escola, da rede pública de ensino, da cidade de Belém. O critério de escolha desta instituição se deu com base em sua história, uma vez que se trata de uma escola-modelo na inclusão de alunos com necessidades especiais. Selecionada a escola foi solicitada à direção a autorização da execução deste projeto, e na sequência selecionada a família a ser investigada.

A partir de então, a coleta de dados iniciou na casa da Davi, com a realização da entrevista, por meio de um roteiro semiestruturado, para o delineamento da estrutura familiar. Em seguida, foi aplicado o FAST, com todos os membros da família. Destaca-se que essas aplicações foram filmadas, com a posterior transcrição das falas, sendo os trechos utilizados na organização dos dados referentes à estrutura e dinâmica familiar.

Observa-se que durante a execução do FAST, Davi apresentou algumas dificuldades de compreensão, a respeito dos conceitos de coesão e hierarquia, o que levou à exemplificação dessas variáveis separadamente, a partir de uma representação genérica de família, antes da realização do teste. Entende-se que essa dificuldade pode estar relacionada ao fato de Davi não participar de nenhum programa de estimulação e/ou acompanhamento pedagógico, dentro ou fora do ambiente escolar, o que dificultou a compreensão dos termos do teste, necessitando de uma exposição prévia numa linguagem detalhada por meio de exemplos. Após a exemplificação e certificando-se que Davi compreendeu os termos, iniciou-se a aplicação do instrumento.

As respostas ao roteiro semiestruturado foram transcritas e em seguida agrupadas por temas de acordo com os tópicos do instrumento: dados demográficos; renda do grupo familiar; características da rede social de apoio da família e questões específicas a respeito do diagnóstico de paralisia cerebral. Após essa transcrição e análise temática, foram pensadas categorias que pudessem agregar esses dados de modo a descrever a estrutura familiar.

Os resultados obtidos pelos instrumentos e pela transcrição da aplicação do FAST foram organizados em três categorias que foram testadas por quatro avaliadores que compuseram o grupo que investiga inclusão do Laboratório de Ecologia do Desenvolvimento (LED). Após a análise e concordância de 90\% entre os avaliadores, o sistema de categorias referente aos dados obtidos com a entrevista ficou constituído da seguinte forma: a) caracterização da família de Davi e b) história de vida de Davi. O sistema de categorias construído com os dados obtidos através do FAST é constituído pela categoria: estrutura e dinâmica familiar em situação de conflito. Estes últimos dados são apresentados através do genograma para representar as variáveis coesão e hierarquia. 


\section{Resultados E Discussão}

\subsection{Caracterização da FAMília de DAVI}

A família investigada caracterizou-se por ser um grupo constituído a partir do recasamento de Carla (34), mãe de Davi (13), com Jorge (24) como pode ser visualizado no genograma abaixo.

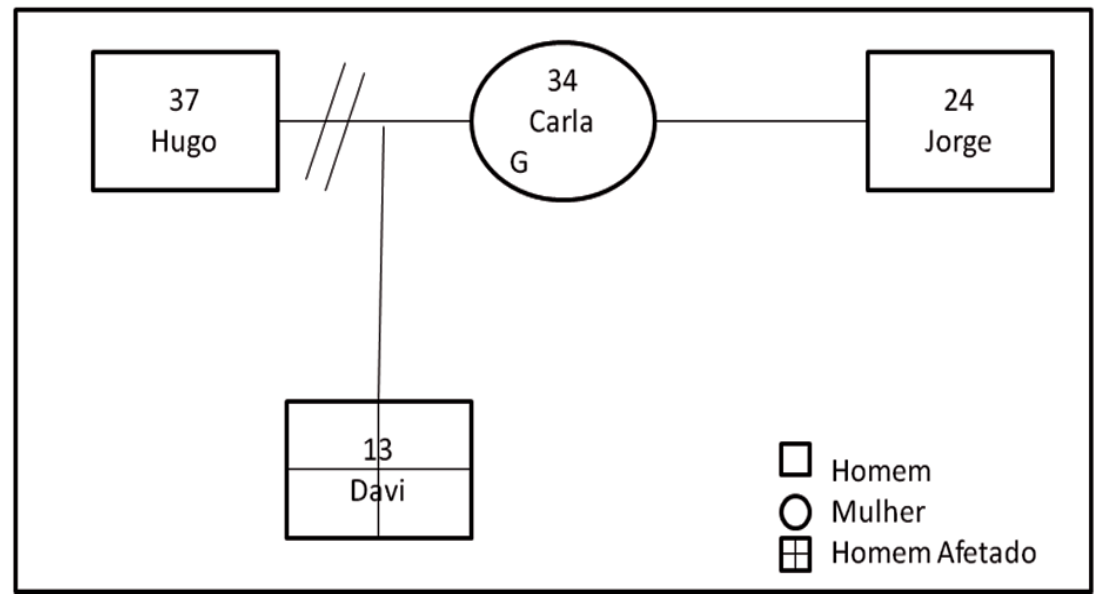

Figura 1 - Genograma da Família de Davi

Carla foi casada com Hugo durante 13 anos, sendo que após sete anos de relacionamento, nasceu Davi, que devido a convulsões e ao quadro de icterícia, desenvolveu paralisia cerebral; desde então, esta união se manteve por mais seis anos. Quando Davi completou 12 anos, Carla iniciou o namoro com Jorge, dividindo o mesmo espaço domiciliar depois de um ano de relacionamento; na época da coleta de dados eles moravam juntos a dois anos, ela estava grávida de cinco meses de um menino, e Hugo visitava Davi somente uma vez por mês, quando levava algum auxílio financeiro ao filho.

Destaca-se nesse arranjo familiar, uma complexidade que pode ser observada em estruturas familiares formadas a partir do recasamento, relatadas por Cano et. al. (2009), que é a diferença no ciclo de vida dos conjugues, pois na medida em que Carla já havia passado pelas experiências de, um casamento, o nascimento de um filho e o divórcio, Jorge ainda não, por tratar-se de seu primeiro relacionamento estável.

\subsection{História de VIDA DE DAVI}

Ao completar seis anos, Davi foi matriculado em uma escola regular perto de sua casa, após o primeiro ano letivo mudou para um Instituto de atendimento específico para crianças com paralisia cerebral, no qual não se adaptou, voltando 
para sua antiga escola regular, onde está até hoje. No momento de realização da pesquisa ele estava cursando a $3^{\mathrm{a}}$ série, sendo que repetiu a $1^{\mathrm{a}}$ por três vezes e a $2^{\mathrm{a}}$ série duas vezes.

O diagnóstico da paralisia cerebral de Davi não foi simples. Após um longo período de avaliações, internações e consultas com diferentes profissionais é que foi diagnosticado com hemiparesia (aos 12 meses de idade). Davi se locomove bem, tem dificuldades na execução de atividades de higiene pessoal, sua fala é um pouco prejudicada devido a dificuldade em manter o tônus muscular, tem dificuldades nas atividades acadêmicas envolvendo cálculo eleitura/interpretação.

O tratamento de Davi oscilou entre cuidados clínicos e cuidados caseiros (remédios a base de ervas, banhos e superstições populares). No início da pesquisa ele não tinha nenhum atendimento especializado e nem frequentava a sala de apoio pedagógico da escola, pois as aulas nessa sala tinham sido suspensas; ao final, ele continuava sem frequentar nenhum programa de fonoaudiologia e/ou fisioterapia, ou terapia ocupacional, assim como a sala de apoio pedagógico que já havia voltado a funcionar.

\subsection{ESTRUTURA E DINÂMICA FAMILIAR EM SITUAÇ̃̃o DE CONFLITO}

Os dados do FAST, representados a partir do genograma da família, possibilitaram a visualização dos resultados de coesão e hierarquia, na representação de conflito (RC) para cada um dos membros, sendo que os escores de coesão estão representados por traços lilás ao redor dos membros, cujo estilo será de acordo com o grau de proximidade, ou seja, traço pontilhado representa baixa coesão, traço contínuo, de espessura média equivale à coesão média e traço contínuo de espessura grossa equivale à alta coesão; e os escores de hierarquia são representados pelo tom de verde, quanto mais escuro o verde mais poder tem aquele membro dentro do grupo. A seguir tem-se as figuras: 


\subsubsection{Coesão e hierarquia na RepresentaÇÃo de Conflito (RC) de CARla}

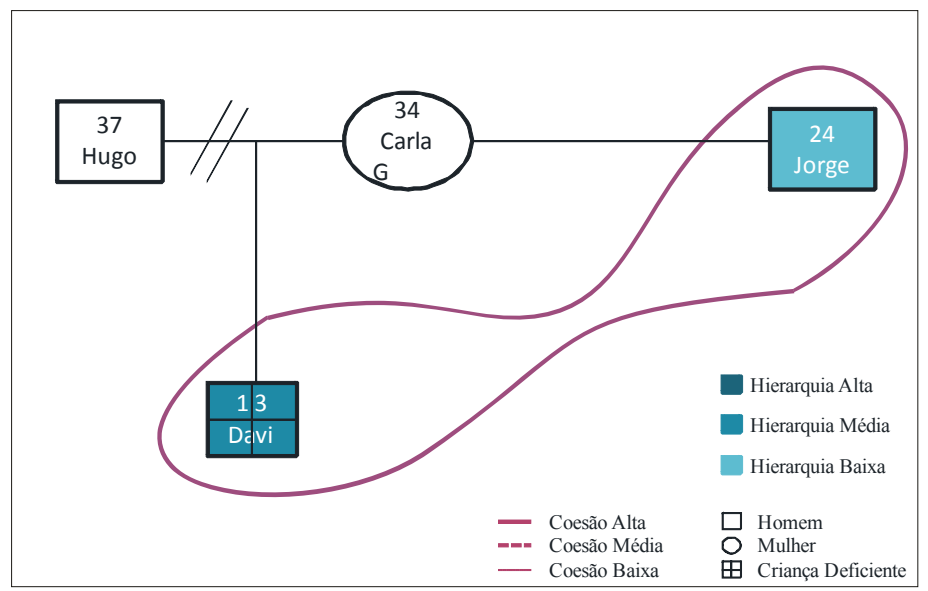

Figura 2 - Percepção de Carla sobre a coesão e a hierarquia na representação familiar em conflito

A representação acima foi construída a partir do relato superficial de Carla sobre pequenos conflitos que ocorrem entre o companheiro e o filho, em decorrência da organização dos objetos na casa, sendo assim não se representa no tabuleiro, mas ao posicionar o filho e o companheiro, o fez um ao lado do outro, distribuindo poder entre os dois; Davi com hierarquia alta e Jorge com hierarquia baixa (inversão de hierarquia) dizendo, 'Sempre é esse [...] o Davi, porque eu sou por ele'.

Dessa forma, Carla demonstra que, por mais que ela não se represente no tabuleiro; em situação de conflito entre Jorge e Davi, ela é quem detém e distribui o poder no grupo, além disso, identifica-se em sua fala, a interpretação da variável hierarquia como um fator de prediletância, durante a explicação do conflito:

É, porque é assim, um quer disputar com o outro a minha atenção. Aí começa a confusão entre eles dois, e o Davi corre pra mim, porque ele tem que correr pra mim, aí começa a confusão entre eu e o Jorge, eu e o Jorge, aí eu digo pro Davi, vai te imbora pra casa da mamãe, tipo assim evitando uma coisa pior. Eu não sou nem a favor nem contra o Davi, porque tipo assim, tem horas que ele passa do limite. Porque trocar ele pelo Jorge eu não troco, então eu prefiro me sair, deixo ele falando sozinho e vou me embora.

Observa-se que a interpretação à distribuição de poder como a representação de preferência entre companheiro e filho reflete um dos conflitos mais presentes na estrutura do recasamento que é o conflito de lealdade entre o amor pelo conjugue e pelo filho, infringindo culpa ao pai biológico pelo sentimento de traição ao filho (CARTER; MCGOLDRICK, 2007). Dessa forma, esse conflito de 
lealdade configura uma distribuição de hierarquia feita por Carla que interfere diretamente no estabelecimento de limites na criação de Davi e nas relações estabelecidas entre ele e Jorge, conforme relatado por ela:

O Davi não obedece ele, mas tem medo dele. Antes ele falava com ele e ele se aquietava logo, hoje não, quando Jorge briga com ele, ele olha pra cara do Jorge e começa a rir [...] aí pra não deixar, eu pego ele e saio já rindo também. Mas nunca dando a razão pra ele, depois eu chamo ele e brigo com ele, não é assim! Vocês tem que se dar bem vocês dois.

Percebe-se que Carla desautoriza Jorge na imposição de limites ao filho, no momento em que sai da discussão rindo do companheiro, na frente de Davi. Essa observação a respeito da fala de Carla coaduna-se com a literatura, na medida em que a identificação de autoridade na família recasada apresenta-se inicialmente prejudicada, pelos conflitos por ela gerados, os quais tem sua resolução a partir da reorganização dessa nova estrutura, que requer de dois a cinco anos para se estabilizar (CARTER; MCGOLDRICK, 2007).

Embora a interferência, de Carla, na interação entre Jorge e Davi, muitas vezes, ocorra desautorizando o companheiro, isso não se dá sem a sua preocupação sobre o relacionamento dos dois, 'Já pensou eu tendo um outro filho, tu vai ficar de lado, primeiro eu quero unir vocês dois, depois que vocês verem que tá tudo ok, aí sim'.

A integração desejada por Carla, assim como a flexibilidade das fronteiras a partir dos papéis desempenhados pelos membros do grupo, se constitui com a passagem do tempo. Portanto, o tempo é uma das variáveis mais importantes nos estudos do recasamento (apud CARTER, MCGOLDRICK, 2007), porque, permite o estabelecimento efortalecimento devínculos, favorece a definição de papéis nas novas redes familiares, o sentimento de pertencer a e consequentemente a co-paternidade. No caso da família de Carla e Jorge, constituída a dois anos, são necessárias estratégias de adaptação não apenas às demandas emocionais e relacionais de uma família recasada, mas também aos cuidados com Davi, seja nas atividades de vida autônoma, nas atividades acadêmicas ou nos atendimentos terapêuticos necessários para a promoção de qualidade de vida de Davi, ou seja, além das demandas do recasamento, as demandas de cuidado geradas pelas características da PC do filho são outro fator que interfere fortemente na dinâmica familiar. 


\subsubsection{CoEsão E HIERARQUia NA REPRESENTAÇÃo DE CONFLITO (RC) DE JORGE}

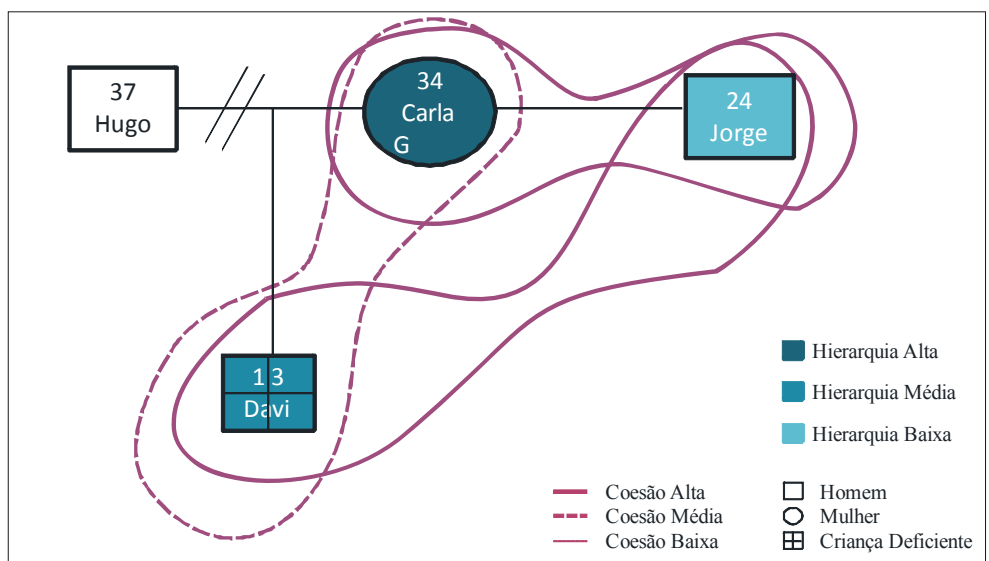

Figura 3 - Percepção de Jorge sobre a coesão e a hierarquia na representação familiar em conflito

Nessa representação, o conflito exposto foi o mesmo relatado por Carla, um conflito entre Jorge e Davi; embora Carla em sua representação de conflito não tenha se posicionado, Jorge além de representá-la, o faz atribuindo à Carla o domínio do grupo, expresso no seu relato:

A gente briga mais aqui por termos de limpeza, porque ele suja aqui e ela quer defender ele, aí eu fico com raiva dela e a gente acaba discutindo, geralmente é com negócio de limpeza, se não tiver limpo! Só em termos de sujar, as vezes ele vem e trás bagulho da rua, larga aqui e vai embora, aí eu cobro e ela defende, aí ele fica na dele, aí ele pega e joga fora, mas quando ela tá aqui muda.

A não distribuição de autoridade parental entre Carla e Jorge, conforme discutido na RC de Carla, não somente concentra nela, o papel de impor limites e ordenar condutas, como também influencia Davi no não cumprimento das regras impostas por Jorge, na presença de Carla. Percebe-se com isso não apenas a dificuldade de Carla em negociar a assunção da co-paternidade com Jorge, como também a dificuldade de Davi em identificar os limites de sua relação com a mãe, muito em virtude do vínculo estabelecido durante os seis anos transcorridos entre a separação e o recasamento de Carla, onde ela se dedicou exclusivamente aos cuidados de Davi.

Alguns fatores apontados na literatura evidenciam-se nessa família como: a bagagem emocional, trazida por Carla e a diferença de ciclo de vida entre o casal, pois enquanto Carla vem de um primeiro casamento e um grande período de tempo entre o divórcio e o recasamento, Jorge depara-se com as demandas de sua primeira relação estável já com os cuidados de uma criança com necessidades especiais. Nesse contexto, ascender ao posto de marido-padrasto requer sua 
entrada nesse vínculo que é mediado por Carla muitas vezes de modo rígido impedindo a entrada do companheiro no grupo.

Ao dispor os bonecos na horizontal, Jorge se posiciona entre Davi e Carla, conferindo uma coesão alta entre ele e Davi, e média entre Carla e Davi. O aumento de proximidade entre Jorge e Davi, embora pareça uma aliança, é uma tentativa de afastar Davi de Carla, pois, por mais que o padrasto esteja em casa, seu contato é efetivo com Davi, apenas na presença da esposa e nos finais de semana, quando o grupo realiza atividades em conjunto, como assistir televisão e alimentar-se, visto que, durante os dias da semana, o maior contato de Davi é com a avó materna, que mora ao lado. Enquanto os papéis não estão definidos claramente, devido a baixa flexibilidade na negociação de autoridade no grupo, a emergência de conflitos e ciúme são comuns.

\subsubsection{Coesão e hierarquia na RePresentação de Conflito (RC) De Davi}

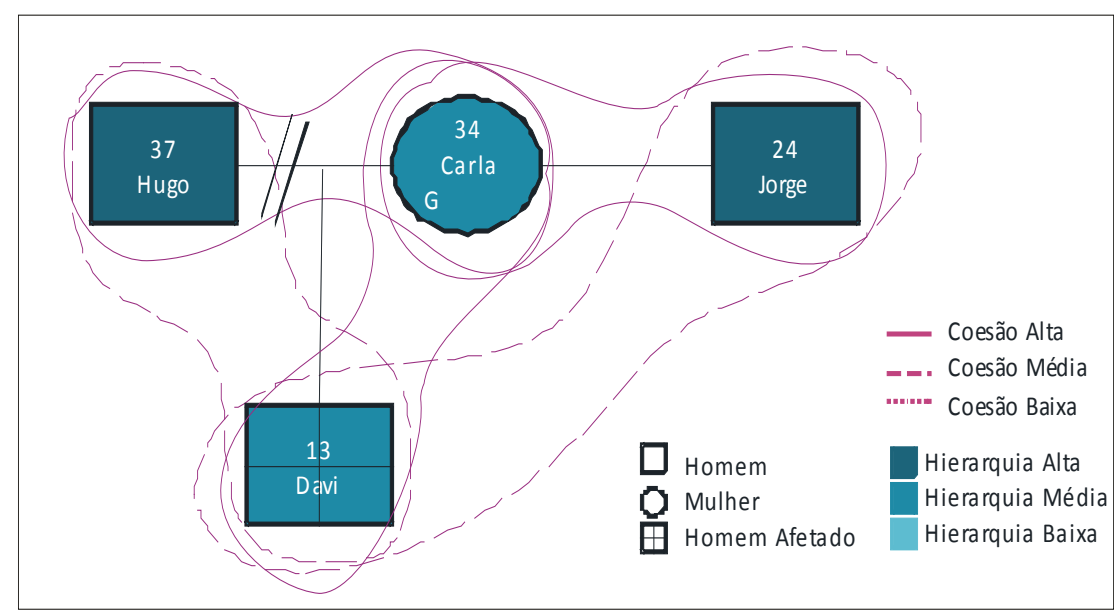

Figura 4 - Percepção de Davi sobre a coesão e a hierarquia na representação familiar em conflito

O conflito acima relatado por Davi, não foi o mesmo representado por Carla e Jorge; estes se limitaram a contar superficialmente uma discussão entre Davi e Jorge, aguçado pelas discordâncias entre o casal, na educação de Davi. Ao passo que Davi representa um conflito entre os pais no qual Jorge interveio à favor da companheira.

Ao representar uma situação de conflito, Davi relata uma discussão, presenciada por ele, entre Carla e Hugo, em decorrência do auxílio financeiro prestado por este a Davi. A coesão foi alta nas díades, Hugo-Carla, Jorge-Carla e Davi-Carla e média nas díades Davi-Hugo e Davi-Jorge, já a hierarquia foi alta, nas figuras do pai e do padrasto e média na de Davi e sua mãe. Nesse conflito o sistema familiar e o subsistema parental apresentaram uma estrutura equilibrada, ambos com coesão e hierarquia médias. 
Essa representação equilibrada, no entanto, não repercutiu em uma flexibilidade nítida entre as fronteiras, uma vez que o sistema familiar foi avaliado, por Davi, com uma fronteira difusa, conferindo um emaranhamento aos subsistemas, o que dificulta a troca de papéis necessária entre eles, para que as funções, de cada um, não sejam descaracterizadas. Visto que, de acordo com Nichols e Schwartz (2007), é necessário que haja algum grau de diferenciação entre os subsistemas, por meio da distribuição de hierarquia no grupo, para que cada membro exerça seu papel de forma clara evitando conflitos, como a disputa pela atenção de Carla.

Observa-se o quanto é importante a presença de uma fronteira nítida, flexível o suficiente para atender a dinâmica das relações estabelecidas a partir do recasamento, ainda mais quando há uma criança com demandas de cuidado específicas como é o caso de Davi. Sendo assim, a interpretação dada pela mãe e padrasto às limitações de Davi, além de sua percepção, acerca de como eles se relacionam com ele e o percebem, são fundamentais na organização das relações estabelecidas dentro do grupo, visto que cada um vai interagir com base na percepção que tem das outras pessoas e do grupo como um todo, configurando um campo comum de desenvolvimento familiar (BRONFENBRENNER; MORRIS, 1998).

\section{CONSIDERAÇÕES FINAIS}

O recasamento pressupõe que para uma nova relação, pelo menos um dos conjugues já tenha sido casado e tenha pelo menos um filho, ou seja, nessa nova constituição familiar, além do vínculo consanguíneo (fator aglutinador predominante nas famílias nucleares), o vínculo conjugal terá maior relevância na estruturação do grupo. A complexidade decorrente do recasamento não se assenta somente no número de membros e/ou o vínculo entre eles, mas nas alterações econômicas e sociais que se iniciam com a separação/divórcio e estendemse à nova relação. Dessa forma, a principal tarefa familiar será a redefinição de papéis, demandando flexibilidade a esse sistema, o que vai depender de fatores como, bagagem emocional dos membros, período entre os casamentos, tempo de recasamento, guarda dos filhos, entre outros.

A dinâmica da família formada por Carla e Jorge é influenciada tanto por algumas características do recasamento, citadas anteriormente, quanto pelas limitações de Davi. Um ponto importante a ser destacado é a influência da bagagem emocional, da cumplicidade entre mãe e filho, no estabelecimento das fronteiras entre os subsistemas, a partir do recasamento, nesse caso, uma fronteira rígida responsável pela manutenção dos padrões da família nuclear, dificultando a aproximação de Jorge, e a consequente construção da co-paternidade.

Ao mesmo tempo em que Carla fala de seu interesse em favorecer a relação entre Jorge e Davi, não se identificou, durante a coleta de dados, atitudes que favorecessem essa aproximação, visto que Carla desautorizou Jorge, na 
medida em que riu, na frente do filho, das regras impostas pelo companheiro para a limpeza da casa, por exemplo. Sendo assim, essa assunção de co-paternidade fica cada vez mais prejudicada, pois além de tempo, requer também disponibilidade dos parceiros; é algo a ser elaborado pelo grupo. Nesse sentido, as características de Davi, suas demandas comunicacionais e cognitivas geradas pela paralisia cerebral, são fatores que exercem forte influência nessa negociação (BRONFENBRENNER; MORRIS, 1998), exigindo mais tempo e estratégias específicas para a integração do grupo familiar. De acordo com a qualidade das relações construídas e o quanto os parceiros estão dispostos a investir nessas relações, as características de Davi podem facilitar ou dificultar esse processo.

Outro fator observado nessa família, que interfere na qualidade dos vínculos é a diferença de ciclo de vida, entre Carla e Jorge, pois, enquanto Carla já passou por um casamento do qual resultou a separação e um filho, Jorge, 10 anos mais novo, está construindo seu primeiro relacionamento estável, deparando-se com emoções e tarefas da paternidade, decorrentes da vinda do filho do casal. Essa diferença é observada, também na vida financeira da família; Carla já possui um emprego fixo ao passo que Jorge, ainda não alcançou essa posição, sendo assim, Carla detém o controle financeiro do grupo e a autoridade emocional.

Essa concentração de poder na figura de Carla coloca-a numa posição mais confortável para expor as relações de maneira equilibrada diferentemente de Jorge e Davi que dividem, entre si, poder e atenção. Percebe-se aí, as tarefas impostas pelo recasamento, a influência das características de Davi e da discrepância do ciclo de vida dos conjugues, na execução dessas tarefas, pois segundo Carter e McGoldrick (2007), essa diferença entre o casal exigirá um trabalho emocional maior do grupo, visto que não se apaga e nem se adquire experiência, de um dia para outro, assim como a construção de vínculos entre Jorge e Davi se dará com o tempo.

A tentativa de impor um comportamento ou estilo de vida ao conjugue limita as tarefas correspondentes ao seu ciclo de vida, gerando conflitos no sistema conjugal que repercutirão no bem-estar da criança. Essa diferença de ciclo de vida exigirá que ambos aprendam a funcionar em várias fases, demandando maior flexibilidade das fronteiras (MINUCHIN, 1990), para que novos papéis sejam agregados e antigos sejam reformulados, a partir do vínculo conjugal.

Uma limitação nesse estudo foi a aplicação do instrumento com Davi, devido suas dificuldades de compreender os conceitos de poder e afinidade envolvidos na aplicação do FAST. Ainda durante a aplicação do instrumento, outra dificuldade foi a impossibilidade de realizar o teste individualmente com a criança, pois além do espaço da casa ser pequeno, a mãe, embora um pouco afastada, acompanhou as respostas do filho.

Nesse momento foi evidente a ligação emocional entre Carla e Davi, pois a cada boneco representado (posição e altura) ele buscava a aprovação da mãe, direcionava o olhar a ela e, somente após a autorização materna seja verbalmente ('pode fazer' / 'faz aí') ou com aceno de cabeça, Davi dirigia-se ao próximo boneco 
e/ou à próxima representação. No entanto, durante a representação de conflito, apesar dos olhares maternos reprovadores, Davi expõe a discussão entre Hugo e Carla, no qual Jorge interveio a favor da companheira; nesse momento a relação demonstrou-se um pouco tensa entre mãe e filho, então Carla relata sucintamente o motivo da discussão entre ela e o pai de Davi (ajuda financeira ao filho).

Acredita-se que esse estudo possa contribuir com outras análises, na medida em que trás à discussão, uma realidade ainda pouco estudada no Brasil, que é o desenvolvimento de crianças com necessidades especiais a partir da interação familiar. A carência de estudos nessa área, além de excluir o grupo familiar como foco de análise, revela uma visão de família como parte da clientela a ser atendida, desconsiderando sua capacidade de, por meio de estratégias, suplantar a necessidade especial do filho, o que reflete, na maioria das vezes, a visão médica de deficiência como suporte para práticas de intervenção, uma visão que precisa ser rompida para promoção de qualidade de vida não apenas para a criança como também para o grupo familiar.

\section{REFERENCIAS}

ARAÚJO, M. R. G. L.; DIAS, C. M. S. B. Papel dos avós: apoio oferecido aos netos antes e após situações de separação/divórcio dos pais. Estudos de Psicologia, Natal, v.7, n.1, p.91101, 2002.

BASIL, C. Os alunos com paralisia cerebral e outras alterações motoras. In: COLL, C.; MARCHESI, A.; PALÁCIOS, J. (Org.). Desenvolvimento psicológico e educação. Trad. Fátima Murad. 2. ed. São Paulo: Artmed, 2004. p.215-233. v. 3

BRONFENBRENNER, U.; CECI, S. J. Nature-nurture reconceptualized in developmental perspective: a bioecological model. Psychological Review, v.101, p.568-586, 1994.

BRONFENBRENNER, U.; MORRIS, P. The ecology of developmental processes. In: LERNER, R. M. Handbook of child psychology: theoretical models of human development. New York, NY: John Wiley \& Sons, 1998. p.993-1027. v.1.

BRONFENBRENNER, U. Environments in developmental perspective: theoretical and operational models. In: FRIEDMANN, S. L.; WACKS, T. D. (Org.). Measuring environment across the life span: emerging methods and concepts. Washington, DC: American Psychological, 1999. p.3-30.

BRONFENBRENNER, U.; EVANS, G. Developmental science in the $21^{\text {st }}$ century: Emerging questions, theoretical models, research designs and empirical findings. Social Development, Chicago, v.9, n.1, p.115-125, 2000.

CANO, D. S. et al. As transições familiares do divórcio ao recasamento no contexto brasileiro. Psicologia: Reflexão e Crítica, Porto Alegre, v. 22, n. 2, p.214-222, 2009.

CARTER, B.; MCGOLDRICK, M. As mudanças no ciclo de vida familiar: uma estrutura para a terapia familiar. 2.ed. $7^{\circ}$ reimp. Tradução de Maria Adriana Veríssimo Veronese. Porto Alegre: Artmed, 2007.

FALCÃO, D. V. S. Doença de Alzheimer: um estudo sobre o papel das filhas cuidadoras e suas relações familiares. 2006. 284 f. Tese (Doutorado em Psicologia) - Programa de PósGraduação em Psicologia. Universidade de Brasília. Brasília, 2006. 
FLECK, A. C.; WAGNER, A. A mulher como a principal provedora do sustento econômico familiar. Revista Psicologia em Estudo, Maringá, v.8, n. especial, p.31-38, 2003.

FREITAS, P. M. et. al. G. Relação entre o estresse materno e a inclusão escolar de crianças com paralisia cerebral. Arquivos Brasileiros de Psicologia, Rio de Janeiro, v.57, n.1, p.46-57, 2005.

GEHRING, T. M. FAST: Family System Test Manual. Zurich: Hogrefe \& Huber publishers, 1993.

GEHRING, T. M.; MARTI, D.; SIDLER, A. Family System Test (FAST): are parent's and children's family constructs either different or similar, or both? Child Psychiatry and Human Development, Switzerland, v.25, n.2, p.125-138, 1994.

GERALIS, E. et al. Crianças com paralisia cerebral: guia para pais e educadores. Trad. Maria Regina Lucena Borges-Osório. 2 ed. São Paulo: Artmed, 2007.

GUERRIERO, I. C. Z.; OLIVEIRA, A.L.; SOUZA, M. T. S. Famílias recasadas: uma análise da literatura psicológica. Psicologia em revista. Belo Horizonte, n. 8, p.77-96, 1999.

MENDES, L. S. A. et. al. Inserção ecológica no contexto de uma comunidade ribeirinha amazônica. Revista Interamericana de Psicologia. Porto Alegre, v.42, n.1, p.1-10, 2008.

MINUCHIN, P. Relationships within the family: a systems perspective on development.

In: HINDE, R.; HINDE, J. S. (Org.). Relationships within families: mutual influences.

Oxford: Clarendon Press e University Press, 1988. p.8-25,.

MINUCHIN, S. Famílias: funcionamento e tratamento. Trad. Jurema Alcides Cunha. Porto Alegre: Artmed, 1990.

NICHOLS, M. P.; SCHWARTZ, R. C. Terapia familiar: conceitos e métodos. 7. ed. Trad. Maria Adriana Veronese. Porto Alegre: Artmed. 2007.

PELISOLI, C.; TEODORO, M. L. M.; DELL'AGLIO, D. D. A percepção de família em vítimas de abuso sexual intrafamiliar: estudo de caso. Arquivos Brasileiros de Psicologia, Rio de Janeiro, v.59, n.2, p.256-269, 2007.

PRATTI, L. E. et al. Revisando a inserção ecológica: uma proposta de sistematização. Psicologia: Reflexão e Crítica, Porto Alegre, v.21, n.1, p.160-169, 2008.

RAMIRES, V. R. R. As transições familiares: a perspectiva de crianças e pré-adolescentes. Psicologia em Estudo, Maringá, v.9, n.2, p.183-193, 2004.

SILVA, S. S. da C. Estrutura e dinâmica das relações familiares de uma comunidade ribeirinha da região amazônica. 2006. 333 f. Tese (Doutorado Psicologia) - Programa de Pós-Graduação em Psicologia, Universidade de Brasília, Brasília, 2006.

SOUZA, R. M. Depois que papai e mamãe se separaram: um relato dos filhos. Psicologia: Teoria e Pesquisa, Brasília, v.16, n.3, p.203-211, 2000.

VITANZA, S. A.; GUARNACCIA, C. A. A model of psychological distress for mothers of children with attention-deficit hyperactivity disorder. Journal of Child and Family Studies, New York, v.8, n.1, p.27-45, 1999.

YIN, R. K. Estudo de caso: planejamento e métodos. 3. ed. Trad. Daniel Grassi. Porto Alegre: Bookman, 2005.

Recebido em: 13/05/2011

Reformulado em: 15/12/2011

Aprovado em: 01/02/2012 